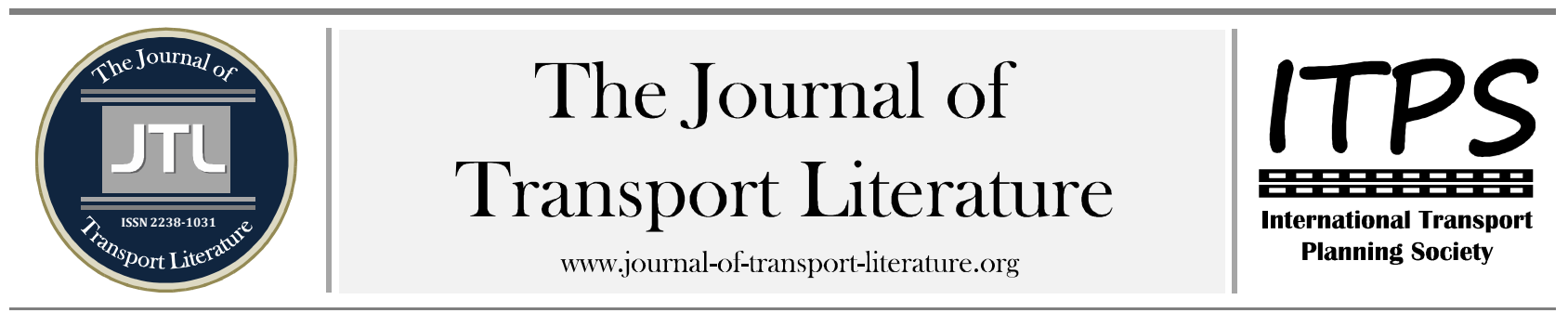

\title{
Predictive modeling of entry flow at rotary intersections in Akure, a developing city and capital of Ondo state, Nigeria
}

Adebayo Oladipo Owolabi+; Olugbenga Joseph Oyedepo; Enobong Etim Okoko

Federal University of Technology, Akure, Nigeria

\section{Article Info}

Keywords:

intersection

traffic parameters

entry flow

model

Submitted 30 Jun 2014;

received in revised form 30 Nov

2014; accepted 28 Dec 2014.

Licensed under

Creative Commons

CC-BY 3.0 BR.

\section{Abstract}

Predictive models for entry flow at rotary intersections in Akure - a developing city in Nigeria- have been developed. Data were collected at the intersections critical to traffic flow in the study area using a cine camera placed at a vantage point from the road sections during peak and off-peak periods in week days. Entry flow $\left(\mathrm{q}_{\mathrm{e}}\right)$ was modelled as a function of circulating flow $\left(\mathrm{q}_{\mathrm{c}}\right)$, delay $\left(\mathrm{d}_{\mathrm{a}}\right)$, headway $(\mathrm{h})$ and geometric features of the intersections. The data were fitted to a multiple linear regression equation to obtain the generalized flow models for peak and off peak periods. The equations obtained were validated using empirical data other than those used to calibrate the model. The adjusted $\mathrm{R}^{2}$ values obtained during the peak and off peak periods were $95.8 \%$ and $87.7 \%$ respectively, indicating that the independent variables (circulating flow, delay and headway) made significant contributions in predicting the entry flow. The models developed can be used to evaluate entry flow at rotary intersections in the study area and other cities in developing countries with similar traffic characteristics for which such models are scarce, thereby facilitating planning and design of effective traffic control mechanisms.

+ Corresponding author. Department of Civil and Environmental Engineering, Federal University of Technology Akure, Nigeria.

E-mail address: bayodistinct@yahoo.com.

\section{Introduction}

Traffic congestion on major roads consequent upon existing bottlenecks at intersections is a major problem especially in metropolitan areas. Intersections are the most critical points from capacity, congestion and safety viewpoints for the operation of an urban road network and have implications on the socio economic workings of a city.

Roundabouts (rotary intersections) that provide traffic control without the use of stop signs or traffic signals-have gained popularity to reduce conflict points, accidents severity, traffic speeds, traffic delay, air pollution, fuel consumption, and construction costs at intersections. When constructed where geometric and traffic conditions are appropriate, they can potentially provide advantages over conventional intersections in terms of capacity reduced, delay, queue length, emissions, increased safety, and aesthetics. A roundabout brings together conflicting traffic streams, allows the streams to safely merge and traverse the roundabout, and exit the streams to their desired directions. The geometric elements of a roundabout also provide guidance to drivers approaching, entering, and traveling through it.

Research on traffic flow prediction at rotary intersections have been focused mainly on cities in developed countries (Kimber, 1980; Troutbeck, 1993; Brilon et.al, 1997), where the traffic situation is very different from those in developing countries; hence this study is intended to formulate predictive traffic flow models for rotary intersections in Akure, Nigeriaa developing city to bring about effective traffic management. It is expected that the developed models would also be applicable to other developing cities with similar traffic characteristics.

In this paper, a brief literature survey is given in Section 1 followed by a description of the methodology for the study in Section 2. The developed models are presented in Section 3 and relevant conclusions drawn.

\section{Brief literature review}

At a roundabout as shown in Figure 1, vehicles circulating around the central island do so in a counterclockwise manner while approaching flows $\left(\mathrm{q}_{\mathrm{a}}\right)$ give priority to circulating flows $\left(\mathrm{q}_{\mathrm{c}}\right)$ (TRB, 2000). This ensures an uninterrupted flow in the circulating roadway. Circulating and approaching flows merge immediately at the entrance to the circulating roadway.

To evaluate the performance of a roundabout, three measures are typically used namely: degree of saturation, delay, and queue length. In all cases, a capacity estimate must be obtained for an entry to the roundabout before a specific performance measure can be computed. Several attempts have been carried out on entry capacity of roundabout and allied models. Some of them are described below. 


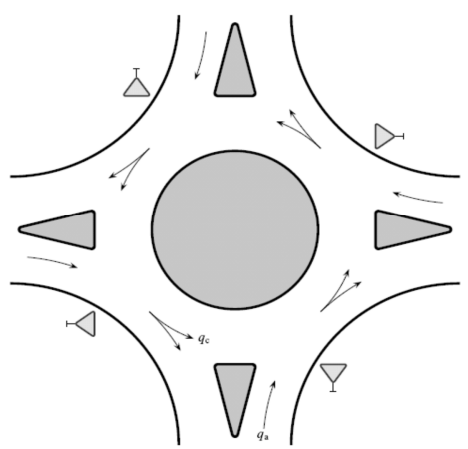

Figure 1 - Direction of movement at a typical roundabout. Source: TRB (2000).

Kimber (1980) who conducted studies in the UK and developed an empirical linear regression equation 1 and equation 2 for single and double lane entry respectively; which was based on a large number of observations at roundabouts operating at-capacity. This equation directly relate capacity to the roundabout geometry.

For Double lane entry:

$$
\begin{array}{ll}
Q_{e}=k\left(F-f_{c} Q_{c}\right), & f_{c} Q_{c} \leq F \\
Q_{e}=0, & f_{c} Q_{c}>F
\end{array}
$$

$$
Q_{e}=2424-0.7159 Q_{c}
$$

where: $Q_{e}$ is entry capacity, vehicles/hour; $Q_{c}$ is circulating flow, passenger car equivalent/hour; and $k, F, f_{c}$ are constants derived from the geometry of the roundabout.

Troutbeck (1991) presented an Australian capacity formula given as:

$$
Q_{e}=\frac{3600 \propto q_{c} e^{-\gamma(T-\Delta)}}{1-e^{\gamma T_{o}}}
$$

in which decay parameter $\gamma$ is defined by

$$
\gamma=\frac{\alpha q_{c}}{1-\Delta q_{c}}
$$

where: $Q_{e}$ is entering capacity (vehicles/hour), $\alpha$ is proportion of free vehicles, $\mathrm{q}_{\mathrm{c}}$ is circulating flow (vehicles/seconds), $\mathrm{T}$ is critical gap (seconds), $\mathrm{T}_{0}$ is follow up time (sec), and $\Delta$ is minimum headway in circulating stream (seconds).

Stuwe (1992) studied eleven German roundabouts and developed the following exponential regression Equation 5 to estimate roundabout entry capacity.

$$
C=A e^{\left(-\frac{B V_{C}}{10,000}\right)}
$$

where: $\mathrm{C}$ is entry capacity (vehicles/hour); $\mathrm{V}_{\mathrm{c}}$ is circulating flow (vehicles/hour); and $\mathrm{A}, \mathrm{B}$ are parameters dependent on the number of circulating and entry lanes.

Troutbeck (1993) conducted studies for the Australian Road Research Board and developed an analytical equation based on gap acceptance characteristics observed and measured at roundabouts operating below capacity. Critical gap and followup times were related to roundabout geometry and capacity was then determined using the Equation 6.

$$
Q_{e}=\frac{\propto Q_{c} e^{-\gamma\left(t_{c}-t_{m}\right)}}{1-e^{-\gamma t_{f}}}
$$

where: $Q_{e}$ is entry capacity (vehicles/hour); $Q_{c}$ is circulating flow (vehicles/hour); $\alpha$ is proportion of non-bunched (free) vehicles in the circulating streams; $\lambda$ is model parameter; $t_{c}$ is critical gap in seconds; $t_{f}$ is minimum headway in circulating streams in seconds; and $t_{m}$ is follow-up time, s.

Owolabi and Adebisi (1993) also developed models for headway data for single lane-traffic flows at some points along Zaria-Sokoto Road, Nigeria. The study was particularly designed to reflect the traffic situation in developing countries like Nigeria where motorcycles constitutes a reasonable proportion of traffic on urban roads. From the Kolmogorov-Smirnov (KS) goodness of fit test results, the composite exponential model was found to be a sound descriptor of observed headways for flows ranging from $170 \mathrm{vph}$ to $750 \mathrm{vph}$; while the shifted negative exponential model was found to be a sound headway model only for low flows. The approximate relationship for cases where motorcycles were included in the observations was:

$$
a=1.07 \times 10^{-3} q-0.06
$$

where: $a$ is the proportion of free vehicles; $q$ is traffic flow expressed in vehicles per hour, while that for data not involving motorcycles was given as:

$$
a=4.510^{-4} q+0.13
$$

Brilon et al. (1997), developed the capacity curve for the urban compact roundabout based on the capacity curves for roundabouts in Germany with single-lane entries and a single-lane circulatory roadway given as:

$$
q_{e, \max }=1218-0.74 q_{c}^{*}
$$

where: $q_{e, \text { max }}=$ entry capacity (passenger car equivalent/hour), $q_{c}^{*}=$ circulating flow (passenger car equivalent/hour)

Polus and Shmueli (1999) developed an exponential regression model in equation based on their studies of six small to medium-sized roundabouts in Israel. The model yielded an exponential reduction in entry capacity with an increase in circulating flow and a significant increase in entry capacity with an increase in outside diameter as shown in equation 10.

$$
C=394 D^{0.31} e^{-\left(0.00095 V_{c}\right)}
$$

where: $\mathrm{C}=$ entry capacity, vph; $\mathrm{D}=$ outside diameter; and $\mathrm{V}_{\mathrm{c}}=$ circulating flow, vph.

The Highway Capacity Manual (TRB, 2000) presented a methodology for estimating roundabout capacity based on gap acceptance. The capacity model presented in Equation 10 is applicable only to single-lane roundabouts with a circulating volume less than $1,200 \mathrm{vph}$. 


$$
C_{e x}=\frac{V_{c x} e^{-V_{c x} t_{c} / 3600}}{1-e^{-V_{c x} t_{f} / 3600}}
$$

where: $\mathrm{C}_{\mathrm{ex}}=$ entry capacity for the entry $\mathrm{x}$ in passenger car units/hour; $\mathrm{v}_{\mathrm{cx}}=$ conflicting flow in front of entry $\mathrm{x}$ in passenger car units/hour; $\mathrm{t}_{c}=$ critical headway in seconds; and $\mathrm{t}_{\mathrm{f}}=$ follow-up time in seconds.

The Highway Capacity Manual (TRB, 2000) also gives the capacity of the critical lane of a multilane roundabout entry as follows:

$$
C_{\text {crit }}=1230 e^{\left(-0.0009 V_{c}\right)} 2.13
$$

where: $\mathrm{C}_{\text {crit }}$ is capacity of the critical lane on the approach in vehicles/hour; and $\mathrm{V}_{\mathrm{c}}$ is Conflicting flow in vehicles/hour.

The capacity of the non-critical lane is assumed to be the same as that of the critical one. The multilane capacity model has two parameters that can be calibrated: the coefficient in front of the exponential term i.e. 1230 and the coefficient within the exponential term i.e. -0.0009. The coefficient in front of the exponential term is equivalent to the follow-up time and can be readily measured in the field.

\section{The study area}

Akure the capital city of Ondo State with a population of 387,087 according to 2006 census, is one of the fastest growing urban settlements in the South Western region of Nigeria. It is located on latitude 70020 " N and longitude 50o 15"E. The existing land use is characterized by a medium density of structure within the inner core areas. Akure is composed mainly of residential areas forming over $90 \%$ of the developed area but additional activities such as warehousing; manufacturing, workshops and other commercial activities are commonly located within the residential neighborhoods. Over the years, the number of vehicles on its roads had increased greatly due to increasing socioeconomic activities. Increase in infra-structural facilities such as housing, electricity, water supply and transportation caused rural -urban migration that imposed serious strains on existing transport infrastructure brought about various traffic problems. The natural pattern of development is linear along its main roads; Oyemekun-Oba Adesida road and Arakale-Oda road. These roads connect other street roads from Aiyedun, Isolo, Araromi, Oke-Ijebu, Elerinla, Fanibi, Isikan and Adegbola residential areas.

In Akure metropolis, unsignalized intersections are the most common forms of intersection where it is controlled by Stop and Yield signs. The traffic composition in the metropolis is mixed comprising of motorcycles, taxis, minibuses, Lorries and trucks (trailers); however, the traffic composition of Akure is dominated by taxis, motorcycles (Okadas) and minibuses (Owolabi, 2009). Figure 2 is the map of Ondo State showing the study area.
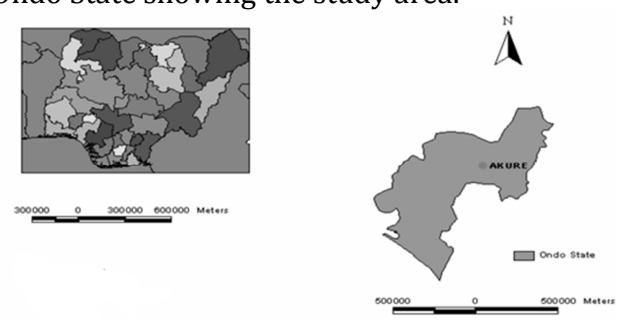

Figure 2 - The map of Ondo State showing the study area. Source: Ogunmodede (2006).

\section{Methodology}

Field studies were conducted at two rotary intersections namely Olukayode (RN1) and Alafiatayo (RN2) shown in figure 3 , being critical to traffic flow in the study area. Traffic parameters were metered using cine camera placed at an elevated vantage point from the road section during the morning and evening peak periods between 7:30-8:30 am and 4:30-5:30 pm respectively and off-peak period between 11:30 am-12:30 pm during week days. Data on speed $\left(\mathrm{V}_{\mathrm{s}}\right)$, density $(\mathrm{K})$, traffic volume (q), headway $(\mathrm{h})$, and delay $\left(\mathrm{d}_{\mathrm{a}}\right)$ were meticulously extracted from the cine camera by replaying it. Speed was measured by taking the travel time as vehicles traversed a short measured distance along the intersection approaches. Density was measured by counting the number of vehicles occupying a given section of the roadway while replaying the cine-camera. The headways were measured between the vehicles while replaying the cine-camera. The control delay was measured by taking note of how long a vehicle waited at a particular approach before having the right-of-way. The entry flow $\left(\mathrm{q}_{\mathrm{e}}\right)$ was expressed as a function of roadway characteristics and geometric features and was fitted to a multiple linear regression using the Statistical Package for Social Scientist (SPSS 16) to obtain the calibrated model equations for selected intersections in the metropolis; the model equations were validated using field data.

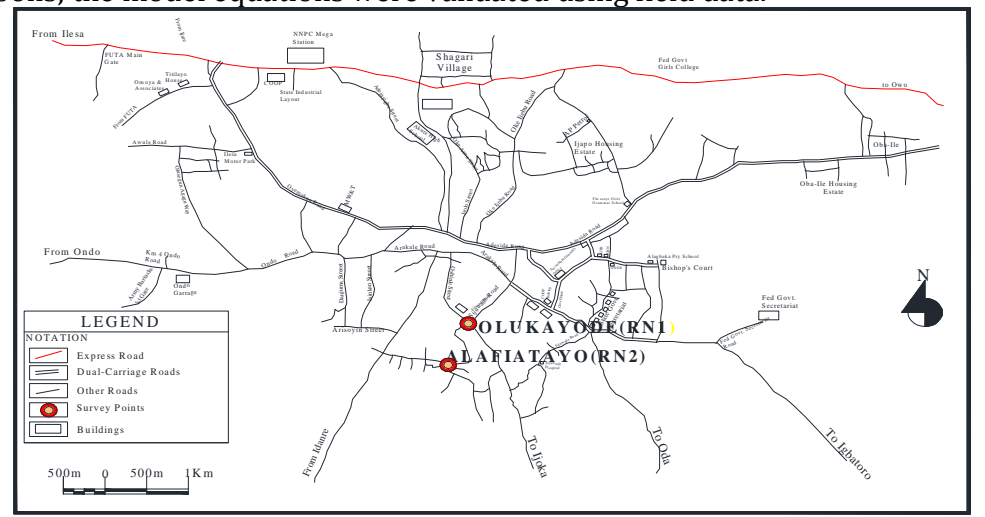

Figure 3 - Street Guide Map of Akure Showing the Survey Points. Source: Ministry of Lands and Housing (2010). 


\section{Results and discussion}

The descriptive statistics of traffic data for the rotary intersections studied during peak and off peak periods are shown in Table 1 and Table 2. In the tables, $q_{e}$ is the entry flow in Vehicles/hour, $q_{c}$ is the circulating flow (Vehicles/hour), $d_{a}$ is the average delay in seconds and $h$ is the headway in seconds.

Table 1 - Descriptive statistics of traffic data during peak periods

\begin{tabular}{|c|c|c|c|c|c|c|c|c|}
\hline $\begin{array}{c}\text { Traffic } \\
\text { Characteristics }\end{array}$ & Mean & Median & Mode & Kurtosis & Skewness & $\begin{array}{l}\text { Standard } \\
\text { Deviation }\end{array}$ & Variance & $\begin{array}{c}\text { Coefficient of } \\
\text { Variance }\end{array}$ \\
\hline $\mathrm{q}_{\mathrm{e}}$ & 994.17 & 990 & 1056 & -0.15 & 0.010 & 71.61 & 5127.38 & 0.072 \\
\hline $\mathrm{q}_{\mathrm{c}}$ & 967.83 & 976 & 976 & 2.42 & -0.99 & 88.88 & 7900.27 & 0.092 \\
\hline $\mathrm{H}$ & 3.78 & 3.68 & 3.64 & 2.77 & 1.30 & 0.39 & 0.15 & 0.10 \\
\hline $\mathrm{d}_{\mathrm{a}}$ & 23.81 & 24 & 24 & -0.13 & 0.02 & 3.27 & 10.70 & 0.14 \\
\hline \multicolumn{9}{|c|}{ Table 2 - Descriptive statistics of traffic data during off peak periods } \\
\hline $\begin{array}{c}\text { Traffic } \\
\text { Characteristics }\end{array}$ & Mean & Median & Mode & Kurtosis & Skewness & $\begin{array}{l}\text { Standard } \\
\text { Deviation }\end{array}$ & Variance & $\begin{array}{c}\text { Coefficient of } \\
\text { Variance }\end{array}$ \\
\hline $\mathrm{q}_{\mathrm{e}}$ & 635.83 & 634 & 632 & 1.10 & 0.24 & 64.66 & 4181.08 & 0.10 \\
\hline $\mathrm{q}_{\mathrm{c}}$ & 639 & 640 & 640 & 8.11 & 1.56 & 81.81 & 6693.11 & 0.13 \\
\hline $\mathrm{H}$ & 5.83 & 5.81 & 5.08 & 1.37 & 1.00 & 0.81 & 0.65 & 0.14 \\
\hline $\mathrm{d}_{\mathrm{a}}$ & 20.19 & 20 & 20 & -0.48 & 0.16 & 4.65 & 21.64 & 0.23 \\
\hline
\end{tabular}

For Rotary Intersection:

$$
q_{e}=f\left(\frac{q_{c} \cdot d_{a} \cdot w_{l} \cdot w_{e} \cdot w_{c} \cdot n_{e}}{h}\right)
$$

where: $w_{l}$ is average entry lane width, we is entry width, $d_{c}$ is central island diameter, $w_{c}$ is circulating road width and $n_{e}$ is the number of entry lanes. Taking the log of both sides gives:

$$
\log q_{e}=\log \left(\frac{q_{c} d_{a} \mathrm{w}_{\mathrm{l}} \mathrm{w}_{\mathrm{e}} \mathrm{w}_{\mathrm{c}} \mathrm{n}_{\mathrm{e}}}{h}\right)=\log q_{c}+\log d_{a}+\log \left(\mathrm{w}_{\mathrm{l}} \mathrm{w}_{\mathrm{e}} \mathrm{w}_{\mathrm{c}} \mathrm{n}_{\mathrm{e}}\right)-\log h
$$

Note: $\log q_{e}, \log q_{c}, \log d_{a}$, and -log $h$ are hereafter referred to as $Q_{e}, Q_{c}, D_{a}$ and $H$ respectively. Average entry lane

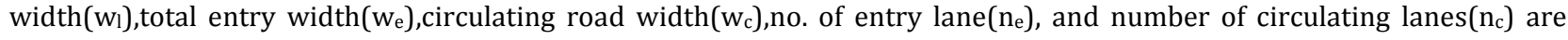
constant; hence they fizzle into the constant term an in the regression equation. Multiple linear regression gives:

$$
Q_{e}=a_{0}+a_{1} Q_{c}+a_{2} D_{a}+a_{3} H
$$

Table 3 and Table 4 give the summary of regression coefficients for the rotary intersection during the peak and off-peak

\begin{tabular}{|c|c|c|c|c|c|c|c|c|c|c|}
\hline \multirow[b]{2}{*}{ Model } & \multicolumn{2}{|c|}{$\begin{array}{c}\text { Unstandardized } \\
\text { Coefficients }\end{array}$} & \multirow{2}{*}{$\begin{array}{c}\begin{array}{c}\text { Standardized } \\
\text { Coefficients }\end{array} \\
\text { Beta }\end{array}$} & \multirow[b]{2}{*}{$\mathrm{T}$} & \multirow[b]{2}{*}{ Sig. } & \multicolumn{2}{|c|}{$\begin{array}{l}\text { 95\% Confidence } \\
\text { Interval for B }\end{array}$} & \multicolumn{3}{|c|}{ Correlations } \\
\hline & B & $\begin{array}{c}\text { Std. } \\
\text { Error }\end{array}$ & & & & $\begin{array}{l}\text { Lower } \\
\text { Bound }\end{array}$ & $\begin{array}{l}\text { Upper } \\
\text { Bound }\end{array}$ & $\begin{array}{l}\text { Zero- } \\
\text { order }\end{array}$ & Partial & Part \\
\hline (Constant) & 2.532 & .045 & & 45.283 & .000 & 1.951 & 2.129 & & & \\
\hline $\mathrm{H}$ & -.505 & .019 & -.608 & -26.824 & .000 & -.542 & -.468 & -.930 & -.890 & -.397 \\
\hline Qc & .279 & .014 & .447 & 20.285 & .000 & .252 & .306 & .892 & .828 & .300 \\
\hline $\mathrm{Da}$ & -.020 & .010 & -.031 & -2.007 & .046 & -.039 & .000 & .194 & -.145 & -.030 \\
\hline
\end{tabular}
period respectively.

Table 3 - Summary of coefficients for rotary intersection during peak period

For Rotary intersection during peak period, substituting the regression coefficients in Table 1 into equation 15 gives:

$$
\begin{gathered}
Q_{e}=2.532+0.279 Q_{c}-0.020 D_{a}-0.505 H \\
\therefore \log q_{e}=\log 10^{2.040}+\log q_{c}{ }^{0.279}+\log d_{a}{ }^{-0.020}+\log h^{-0.505} \\
q_{e}=10^{2.532} \cdot q_{c}^{0.279} \cdot d_{a}{ }^{-0.020} \cdot h^{-0.505}
\end{gathered}
$$

Therefore, the model for rotary intersection during peak period is given as:

$$
q_{e}=340.41 q_{c}^{0.279} \cdot d_{a}{ }^{-0.02} \cdot h^{-0.505}
$$

\begin{tabular}{|c|c|c|c|c|c|c|c|c|c|c|c|}
\hline \multirow[b]{2}{*}{ Model } & & \multicolumn{2}{|c|}{$\begin{array}{l}\text { Unstandardized } \\
\text { Coefficients }\end{array}$} & \multirow{2}{*}{\begin{tabular}{|c|}
$\begin{array}{c}\text { Standardized } \\
\text { Coefficients }\end{array}$ \\
Beta
\end{tabular}} & \multirow[b]{2}{*}{$\mathrm{T}$} & \multirow[b]{2}{*}{ Sig. } & \multicolumn{2}{|c|}{$\begin{array}{l}\text { 95\% Confidence } \\
\text { Interval for B }\end{array}$} & \multicolumn{3}{|c|}{ Correlations } \\
\hline & & B & Std. Error & & & & $\begin{array}{l}\text { Lower } \\
\text { Bound }\end{array}$ & $\begin{array}{l}\text { Upper } \\
\text { Bound }\end{array}$ & $\begin{array}{l}\text { Zero- } \\
\text { order }\end{array}$ & Partial & Part \\
\hline 1 & (Constant) & 2.119 & .076 & & 23.576 & .000 & 1.638 & 1.940 & & & \\
\hline & $\mathrm{H}$ & -.517 & .028 & -.698 & -18.772 & .000 & -.571 & -.462 & -.820 & -.890 & -.674 \\
\hline & Qc & .401 & .031 & .470 & 12.624 & .000 & .326 & .447 & .638 & .796 & .453 \\
\hline & $\mathrm{Da}$ & -.037 & 013 & -.100 & -2.764 & .007 & -.064 & -.010 & -.098 & -.277 & -.099 \\
\hline
\end{tabular}

Similarly, the regression coefficients were substituted to obtain the model equations during the off-peak periods.

The model for Rotary Intersection during Off-Peak Period is given as:

$$
q_{e}=131.52 . q_{c}^{0.401} \cdot d_{a}^{-0.037} \cdot h^{-0.517}
$$

Table 4 - Summary of coefficients for rotary intersection during off peak period

Equations 19 and 20 above show that circulating flow $\left(\mathrm{q}_{\mathrm{c}}\right)$, delay $\left(\mathrm{d}_{\mathrm{a}}\right)$ and headway $(\mathrm{h})$ made significant contributions in predicting entry flow $\left(\mathrm{q}_{\mathrm{e}}\right)$. da and $\mathrm{h}$ made negative impact on the model while qc made a positive contribution. Thus, increase in $\mathrm{q}_{\mathrm{c}}$ will lead to increase in the value of $\mathrm{q}_{\mathrm{e}}$. Table 5 shows summary of the model parameters from statistical analysis output.

From the output summary shown above the adjusted $\mathrm{R}^{2}$ values indicate that: The percentages of independent variables that are explained at RN1 and RN2 are 0.958 and 0.877 respectively. The developed models were validated using empirical data other than those used to calibrate the model in the first place, by comparing the predicted and observed flows. The standard residuals are within -3 and +3 which is an acceptable range. Hence there is a relatively good level of association between the observed and predicted values. 
Table 5 - Summary of the model parameters

\begin{tabular}{|c|c|c|c|c|c|c|c|c|c|c|}
\hline Intersection & $\mathbf{R}$ & $\mathbf{R}^{2}$ & $\begin{array}{l}\text { Adj } \\
R^{2}\end{array}$ & SEE & Source & SS & df & MS & F & Sig. \\
\hline \multirow{3}{*}{$\begin{array}{l}\text { Rotary Peak } \\
\text { Period }\end{array}$} & 0.979 & 0.959 & 0.958 & 0.00916 & Regression & 0.367 & 3 & 0.122 & $1.460 \mathrm{E} 3$ & 0.000 \\
\hline & & & & & \begin{tabular}{|l|l} 
Residual Error \\
\end{tabular} & 0.016 & 188 & 0.000 & & \\
\hline & & & & & \begin{tabular}{|l} 
Total \\
\end{tabular} & 0.383 & 191 & & & \\
\hline \multirow{3}{*}{$\begin{array}{l}\text { Rotary Off- } \\
\text { Peak Period }\end{array}$} & 0.939 & 0.881 & 0.877 & \begin{tabular}{|l|l|}
0.01597 \\
\end{tabular} & Regression & 0.174 & 3 & 0.058 & 227.643 & 0.000 \\
\hline & & & & & Residual Error & 0.023 & 92 & 0.000 & & \\
\hline & & & & & \begin{tabular}{|l} 
Total \\
\end{tabular} & 0.198 & 95 & & & \\
\hline
\end{tabular}

\section{Conclusion}

This study formulated entry capacity equation for a single-lane rotary intersection during the peak and off-peak periods using data obtained from Akure in Nigeria. Traffic parameters such as circulating flow $\left(\mathrm{q}_{\mathrm{c}}\right)$, delay $\left(\mathrm{d}_{\mathrm{a}}\right)$ and headway $(\mathrm{h})$ made significant contributions in predicting entry flow $\left(\mathrm{q}_{\mathrm{e}}\right)$. However, both $\mathrm{d}_{\mathrm{a}}$ and $\mathrm{h}$ made a negative impact on the model while $\mathrm{q}_{\mathrm{c}}$ made positive contributions. Thus, increase in $\mathrm{q}_{\mathrm{c}}$ will lead to increase in the value of $\mathrm{q}_{\mathrm{e}}$. This simple relationship is capable of providing accurate predictions of roundabout entry capacity. The generalized flow equations can be used to evaluate entry flow and used for planning and design of effective control mechanisms at intersections in the study area and in other cities with similar traffic characteristics

\section{Acknowledgements}

The authors wish to express their profound gratitude to Dr. Oluwadare, Mr Emmanuel, Mr. David and final year students of transportation engineering option in the Civil and Environmental Engineering Department of the Federal University of technology, Akure, Nigeria for their immense support during data collection and processing.

\section{References}

Brilon, W., Wu, N., \& Bondzio, L. (1997). Unsignalized Intersections in Germany: A State of the Art. In M. Kyte (ed.), Third International Symposium on Intersections without Signals. Portland, Oregon, USA, 61-70.

Kimber, R. M. (1980). The Traffic Capacity of Roundabouts. TRRL Laboratory Report LR 942. Transport and Road Research Laboratory, Crowthorne, England.

Owolabi A. O., \& Adebisi, O. (1993). Mathematical Models for Headways in Traffic Streams; NSE Technical Transactions (28) 4.

Ogunmodede, E. F (2006). Map of Ondo State. Regional Centre for Training in Aerospace Surveys, Obafemi Awolowo University Ile - Ife Osun State Nigeria.

Polus, A., \& Shmuel, S. (1999). Entry Capacity at Roundabouts and Impact of Waiting Times. Road and Transport Research, 8(3), 43-54.

Stuwe, B. (1992). Investigation of Capacity and Safety at German Roundabouts. Publication of the Institute for Transportation and Traffic Engineering at the Ruhr-University Bochum, 10.

Transportation Research Board (2000). Special Report 209, Highway Capacity Manual 2000. Washington D. C.

Troutbeck, R. J. (1991). Recent Australian Unsignalised Intersection Research and Practices, Intersection without Traffic Signals II. Werner Brilon (Ed.), Springer-Verlag, 238-257.

Troutbeck, R. J. (1993). Capacity and Design of Traffic Circles in Australia, Transportation Research Record 1398, Transportation Research Board, National Research Council, Washington, D.C. 68-74. 